\title{
O PROCEDIMENTO BIOPSICOSSOCIAL: DA PERÍCIA À HABILITAÇÃO/REABILITAÇÃO PROFISSIONAL
}

\author{
José Ricardo Caetano Costa ${ }^{1}$ \\ Ana Maria Correa Isquierdo ${ }^{2}$
}

\section{RESUMO}

Buscamos demonstrar, com o presente trabalho, a necessária inter-relação entre as três áreas que abrangem a seguridade: Saúde, Previdência Social e Saúde. Através do método indutivo, com pesquisa bibliográfica e análise de dados sobre o processo de reabilitação, será analisada a produção sobre o modelo biopsicossocial, no âmbito administrativo (INSS) ou judicial. Os resultados apresentados na amostragem do processo de habilitação e reabilitação profissional realizados no ano de 2015 , em Pelotas, RS, proporcionam elementos que nos permitem concluir a ineficácia deste procedimento, bem como sua faceta não biopsicossocial.

Palavras-chave: Pericia Biopsicossocial. Previdência Social. Seguridade.

\section{HE BIOPSYCOSOCIAL PROCEDURE: FROM EXPERIENCE TO PROFESSIONAL ENHANCEMENT / REHABILITATION}

\begin{abstract}
We seek to demonstrate, with the present study, the necessary interrelation between the three areas that cover safety: Health, Social Security and Health. Through the inductive method, with bibliographical research and data analysis about the rehabilitation process, the Production on the biopsychosocial model, in the administrative (INSS) or judicial scope. The results presented in the sampling of the process of habilitation and professional rehabilitation carried out in the year 2015, in Pelotas, RS, provide elements that allow us to conclude the ineffectiveness of this procedure, as well as its nonbiopsychosocial facet.
\end{abstract}

Keywords: Biopsychosocial Expertis; Social Security; Security.

\section{NOTAS INTRODUTÓRIAS}

\footnotetext{
${ }^{1}$ Professor do Mestrado em Direito e Justiça Social da FADIR/FURG

${ }^{2}$ Mestre em Direito e Justiça Social pela FADIR/FURG. Possui graduação em Direito pela Universidade Católica de Pelotas (2001), com especialização em Direito de Família e Sucessões (ULBRA) e Direito do Trabalho e Previdenciário (FACULDADES ATLÂNTICO SUL/PELOTAS). Advogada associada do escritório de advocacia ISQUIERDO E COSTA ADVOGADOS ASSOCIADOS. Tem experiência na área de Direito, com ênfase em Direito, atuando principalmente nos seguintes temas: direito previdenciário, justiça social, políticas públicas, assistência social e beneficio assistencial.
} 
A Perícia Bipsicossocial vem sendo construída, em termos de sua aplicação campo dos direitos sociais relacionados à Seguridade Social, no mínimo nos últimos cinco anos (COSTA 2014; MAUSS; COSTA, 2015; SERAU Jr.; COSTA 2015 e SERAU Jr.; COSTA, 2016).

Parece, muito embora haja uma forte resistência no campo da Previdência Social, ser caminho sem volta a concepção do adoecimento sob seus diversos outros aspectos: físico, mental, ambiental, de acessos diversos (informação, às políticas públicas etc.), atitudinal, social, econômico entre outros.

A questão central, que pretendemos levantar neste artigo pode ser assim resumida: se o modelo perícial deve ser o biopsicossocial, e parece não pairar mais dúvidas neste sentido, também deve ser biopsicossocial o processo de habilitação e reabilitação profissional à cargo do INSS.

Não é de todo compreensível que, na perícia complexa (médica e social), o segurado tenha considerada as várias idiossincrasias que o rodeia, além da patologia que apresenta, e no decorrer do processo de habilitação/reabilitação não encontre este mesmo tratamento.

Pretendemos demonstrar, portanto, que a própria natureza desse processo é inter e multidisciplinar, ou seja, biopsicossocial.

\section{A INTERRELAÇÃO DAS POLITICAS DE PROTEÇÃo SOCIAL: SAÚDE, PREVIDÊNCIA E ASSISTÊNCIA}

Pretendemos fazer uma análise das três áreas que compõe a Seguridade Social, justamente para demonstrarmos a falta de conexão e correspondência entre elas, em notório prejuízo aos trabalhadores que adoecem.

A Constituição Federal de 1988, conclamada como “cidadã" em virtude da confluência de inúmeros anseios populares e o vasto elenco de direitos sociais nela consagrados, trouxe uma concepção de segurança social nunca inscrito em nenhuma Constituição anterior. No seu artigo 194, a Seguridade Social restou compreendida como um conjunto integrado de ações de iniciativa dos Poderes Públicos e da sociedade, destinadas a assegurar os direitos relativos à saúde, à previdência e à assistência social. 
A Seguridade Social, portanto, enquanto gênero, é formada pela Previdência, Saúde e Assistência Social. Vejamos, muito resumidamente, a configuração de cada uma destas áreas, que devem ser vistas em conjunto.

A) PREVIDÊNCIA SOCIAL: Garantindo aos segurados inscritos no Regime Geral de Previdência Social (RGPS) um conjunto de benefícios que vai desde a aposentadoria por idade a diversos auxílios, passando pela pensão por morte e as aposentadorias por tempo de contribuição (e especial, espécie de aposentadoria por tempo reduzido), possui caráter de seguro social, essencialmente contributivo. Para fazer jus a ela é necessário o preenchimento de vários requisitos, cujo número de contribuições, períodos de carência e outros requisitos, são fixados pela legislação ordinária. É de se frisar que esta concepção vem desde Otto von Bismarck, a tal ponto que a seguridade social, no mais das vezes, é tomada como sinônimo de previdência ou seguro social.

B) ASSISTÊNCIA SOCIAL. Ao contrário da primeira espécie que compõe a seguridade social, não possui caráter contributivo. Exposta e garantida como direito fundamental social no artigo 203, da $\mathrm{CF} / 88$, dela fazem jus todos os cidadãos que necessitam do auxilio pecuniário para proverem seus mínimos sociais e existenciais. $\mathrm{O}$ Benefício de Prestação Continuada da Lei Orgânica da Assistência Social (LOAS) foi introduzido por força da Lei n. 8.742/93, buscando atender aos idosos (hoje com 65 anos ou mais) e aos deficientes e portadores de incapacidade duradoura (dois anos ou mais), que não pudessem manter sua subsistência de forma digna, seja pela idade avançada, seja por outro infortúnio que tenha lhe retirado estas condições. Ocorre que esse processo de concepção deste direito fundamental social enquanto direito, e não mera ajuda ou auxílio assistencial, ainda não foi efetivado: seja no âmbito da Previdência Social, cujo nefasto critério da renda familiar per capita inferior ao $1 / 4$ do SM torna inelegível grande parcela dos que buscam esse direito, seja no âmbito do Judiciário Federal, cujas perícias médicas ainda não atentaram para as idiossincrasias deste importante benefício de atendimento aos mínimos sociais.

C) SAÚDE: Vista como principal função do Estado a partir do movimento Sanitarista, ocorrido na Primeira República, as políticas de Saúde tiveram, no Brasil, um embricamento com a Previdência Social. Isso porque, a partir de 1923, por meio da Lei Eloy Chaves, as Caixas de Aposentadorias e Pensões (IAP's) passaram a fornecer, mas 
somente para os trabalhadores das empresas que tinham estes Entes organizados, alguns direitos na área da Saúde (medicamentos, primeiros socorros, entre outros). A partir de 1930, o governo Getúlio Vargas operacionalizou a fusão destes Institutos em Institutos de Aposentadorias e Pensões (IAP's), que passaram a ter um caráter mais abrangente, muito embora nada universal, eis que atendia os trabalhadores conforme o setor em que laboravam (bancários, comerciários, industriários, marítimos etc.). Mesmo assim, embora pouco ampliada, as prestações relativas à Saúde ficaram à cargo dos IAP's, não cobrindo outros trabalhadores não filiados ao sistema laboral, à exemplo dos rurais e das trabalhadoras domésticas, somente para citarmos os dois principais exemplos. Com o governo militar, a partir de 1964, operacionalizou-se a fusão dos IAP's, com a criação do Instituto Nacional de Previdência Social (INPS), com visível fortalecimento ao sistema privado de saúde e o fortalecimento dos denominados "complexo médicoempresarial." Somente a partir da CF/88 é que a Saúde ganha contornos de universalidade, passando a ser entendida como "obrigação do Estado e direito do cidadão", independentemente de qualquer contribuição vertida ou de filiação laboral.

A gestão destas três espécies também ganharam contornos específicos. A Saúde é organizada a partir do Sistema Único de Saúde (SUS), estando a cargo do Ministério da Saúde. A Previdência Social é vinculada ao Ministério da Previdência e Assistência Social, sendo gestionada pelo Instituto Nacional do Seguro Social (INSS), autarquia pública com personalidade própria criado em 1990 como fruto da fusão entre o INPS e o IAPAS. A Assistência Social, por seu turno, foi a última das espécies da Seguridade Social a ser regulamentada. Após praticamente cinco anos da promulgação da Carta Política de 1988, o que veio a ocorrer por meio da Lei n. 8742/93. E para agravar, o que demonstra o caldo cultural e político ainda existente no Brasil, seu único benefício de prestação continuada foi efetivado no começo de 1997. Somando esse déficit, teremos oito anos de atraso na efetivação, por parte do Estado, no cumprimento do preceito constitucional. Para agravar mais ainda, os beneficiários deste benefício, no valor do salário mínimo legal, deverão atenderem aos requisitos de miserabilidade total e absoluta, haja visto o nefasto critério da renda mensal "per capita" inferior a $25 \%$ do salário mínimo. Além disso, nos casos de deficiência, restou inicialmente exigida a incapacidade para os atos da vida civil, tornando mais distante o preenchimento deste critério para aqueles que detinham alguma deficiência ou incapacidade. 
Com efeito, muito embora represente um inegável avanço, sob o ponto de vista dos direitos sociais e sua efetivação, a concepção de Seguridade Social deve ser vista com cuidado. Sua feição é do tipo bismarckiana, calcada no sistema contributivo do seguro social. Serão os trabalhadores e demais cidadãos produtivos (empresários, autônomos etc.) que manterão o sistema de seguro (leia-se, previdência) social. A concepção de seguridade, tal como a conhecemos e foi cunhada no Texto Constitucional, não se apresenta como uma concepção universalista e integradora: aos contribuintes do sistema é garantido os direitos, aos demais é assegurada uma assistência mínima que busca manter os mínimos sociais indispensáveis à sobrevivência do indivíduo.

Diferentemente da concepção beveridgeana ${ }^{3}$, que busca ampliar o campo do seguro a todos os cidadãos, "aumentando os benefícios até o nível de subsistência e tornando-os adequados no tempo" (BEVERIDGE, 1943, p.458), a concepção de seguro é restritiva, cabendo somente aos que contribuem pecuniariamente com o sistema.

Propomos um repensar da seguridade social, bem como das três espécies que a compõe, na perspectiva trazidas pelo modelo beveridgeano, na compreensão de que o sistema de corte bismarckiano demonstrou-se insuficiente para responder não somente às demandas mas a um modelo de Estado Protecionista dos direitos sociais.

Em se tratando do processo de recuperação e reinserção dos trabalhadores novamente ao mercado de trabalho, por terem perdido as funções originárias, seja por acidente ou outra causa, a interligação entre a Saúde, a Previdência e a Assistência Social passa a ser condição fundamental para que esse processo vingue.

\section{O PROCESSO DE HABILITAÇÃO/REABILITAÇÃO PROFISSIONAL DOS TRABALHADORES}

Os procedimentos de recuperação dos trabalhadores, de modo que possam retornar a exercer novamente suas atividades laborais ou outra de complexidade diferente, sempre estiveram presentes no âmbito da seguridade social como um todo.

\footnotetext{
${ }^{3}$ Sir Willian Beveridge apresentou à Coroa Britânica um relatório, que levou o seu nome, no ano de 1942 , em que aponta as principais causas da miséria e as possíveis frentes que devem ser criadas para o enfrentamento dos riscos sociais.
} 
$\mathrm{Na}$ verdade, desde as Caixas de Aposentadorias e Pensões (CAPs), onde várias delas ofereciam serviços médicos e de assistência aos acidentados no trabalho, uma incipiente espécie de reabilitação era encontrada. Na fusão das CAPs com os Institutos de Aposentadorias e Pensões (IAP's), restou mais visível a preocupação com a recuperação e reinserção dos trabalhadores quando não mais detinham a capacidade laboral.

O Instituto de Aposentadorias e Pensões dos Industriários (IAPI), por sua vez, foi o primeiro Instituto a regulamentar esse procedimento no âmbito dos benefícios, por meio do Dec. n. 44.770, de 3 de novembro de 1958. Este Decreto criou a Comissão de Reabilitação Profissional e Serviço Social, a qual ficou encarregada de implantar, organizar e executar os serviços de reabilitação profissional. (ROSA, s/d)

Percebe-se, pela leitura do artigo 53 da Lei Orgânica da Previdência Social (LOPS), aprovada pela Lei n. 3.807, de 26 de agosto de 1960, que esse dispositivo do IAPI embasou a construção do que veio a ser denominado de Readaptação Profissional. ${ }^{4}$

Na LOPS de 1960, por sua vez, encontramos esse procedimento de forma muito rica e proveitosa aos trabalhadores que adoecem e perdem sua capacidade laboral. Algumas das ideias que hoje cogitamos, como veremos a seguir, já estavam dispostas nos cinco longos artigos do Regulamento Geral da Previdência Social há quarenta e seis anos atrás.

Vejamos, pela importância que esse processo reabilitatório possui para os fins deste trabalho, os principais pontos constantes nesse procedimento reabilitatório:

a) Primeiro, é de se observar que a reabilitação é compreendida como um processo inter e multidisciplinar, que envolve os médicos, assistentes sociais, psicólogos e outros profissionais, sendo a decisão final tomada em conjunto;

b) Segundo, é permitido ao beneficiário do programa, por oportunidade, desnecessidade ou impossibilidade técnica do tratamento, recusar o tratamento apontado (inc. III, art. 171);

\footnotetext{
${ }^{4}$ É de frisar que o as primeiras manifestações a cerca deste processo o vinculava a um procedimento de reeducação profissional, com um viés educativo e pedagógico.
} 
c) Terceiro, além da orientação, formação profissional e colocação ou reemprego, caberá à equipe encarregada do processo indicar o tratamento adequado, assim como acompanhar o caso até a plena reabilitação profissional do trabalhador;

d) Quarto, os cursos para formação e treinamento deverão ser oferecidos não somente no inicio do processo, mas mantidos de forma periódica, de modo a assegurar a garantia e efetividade do retorno do segurado ao trabalho.

Além destes pontos, merecem uma reflexão mais detida mais dois dispositivos constantes na LOPS de 1960. O primeiro, o fato de a assistência médica dos órgãos locais poder requer o encaminhamento de um segurado que está em tratamento, mas não em gozo de um benefício de auxílio-doença, para que possa realizar o processo de readaptação profissional. Vejamos, atualizando essa ideia para os dias atuais, que um segurado é atendido em um Posto de Saúde no SUS e o médico que o atendera perceba, pela patologia que o trabalhador apresenta e diante de sua própria experiência ordinatória cotidiana, que há um risco grande de perder seu emprego devido à patologia e suas implicações. Encaminhar este segurado a um processo prévio de readaptação laboral atende aos fins de proteção social que a Seguridade é imbuída desde seu nascedouro. Isso sem falar na economia que o erário da Seguridade terá quando deixa de arcar com anos a fio com um benefício por incapacidade, quando poderia, antes da perda do emprego, ter encaminhado preventivamente o segurado para a reabilitação.

O segundo ponto que merece destaque encontra-se no artigo 174 da LOPS/60, cuja importância e atualidade merece a citação literal do dispositivo: Fora dos casos previstos nos $\S \S 1^{\circ}$ e $2^{\circ}$ do art. 52, será permitido ao beneficiário, que esteja em processo de reabilitação profissional, e tenha possibilidade, ainda que parcial, de auferir alguma remuneração pelo exercício de atividade para a qual já esteja habilitado, acumular o provento do benefício om essa remuneração, até o dobro do valor daquele, reduzindo-se proporcionalmente este valor na medida em que a remuneração alcançar o limite mencionado." A ideia é bastante interessante e também atual, podendo assim ser traduzida: um segurado poderá, mesmo em processo reabilitatório, conseguir novo emprego e começar a receber salários como empregado, sem a perda de continuidade da participação do processo e sem a perda do benefício que vem recebendo da Previdência Social. Quando conseguir auferir o dobro do valor do benefício, que vai perdendo gradativamente o valor até desaparecer totalmente o encargo da Previdência Social. Por 
certo que esta medida é um verdadeiro incentivo a um processo sério e consequente de reabilitação do segurado. Até mesmo porque ele não deseja permanecer eternamente realizando cursos, oficinas e tentando nova recolocação profissional. Por outro lado, caso não lhe seja garantido um procedimento verdadeiramente eficaz, sério e consequente, o benefício previdenciário torna-se sua única fonte de subsistência.

Uma sistemática adotada pela LOPS de 1960, que diz respeito diretamente ao processo de reinserção (ou não) dos segurados ao mercado de trabalho, merece ser citada pela atualidade que julgamos possuir. Trata-se do direito à Aposentadoria por Invalidez constante no artigo 27, que assim dispôs: “A aposentadoria por invalidez será concedida ao segurado que, após haver percebido auxílio-doença pelo prazo de 24 (vinte e quatro) meses, continuar incapaz para o seu trabalho e não estiver habilitado para o exercício de outro, compatível com suas aptidões.

O que vale dizer, seguindo esta sistemática adotada na legislação de 1960, que a Previdência Social têm o prazo razoável de dois anos para tentar observar o desenrolar da patologia e do estado de saúde laboral do segurado. Passado esse tempo, impõe-se conceder a aposentadoria por invalidez compulsória e automaticamente, ao invés de o deixar esperando por décadas, como acontece na atualidade.

E mais, este dispositivo avança e garante, ainda, que não é necessário o gozo do benefício do auxílio-doença para ser concedida a aposentadoria por invalidez, desde que fundada em exames e análise prévia que aponte pela incapacidade total e definitiva para o trabalho.

Por certo que o entendimento constante neste dispositivo é o de que cabe à Previdência Social manter e oferecer o serviço de reabilitação/habilitação profissional à seu encargo, à contento com os interesses dos segurados, e não contra estes. Incumbe a si esse processo, e não ao segurado que é a parte mais fraca e hipossuficiente, dependendo desta política pública de proteção e segurança social para prover os mínimos sociais.

Lamentavelmente, a Consolidação das Leis da Previdência Social (CLPS), instituída durante o Governo Militar e 1977, por meio do Decreto n. 77.077, apresenta somente um artigo, evasivo e abstrato, prevendo tão-somente que se trata de assistência 
reeducativa e de readaptação profissional, a que tem direito aqueles segurados que recebem auxílio-doença e os aposentados e pensionistas inválidos, à cargo da ABBR (Associação Brasileira de Reabilitação) e outras instituições de carácter privado.

Na CLPS de 1984, instituída pelo Decreto n. 89.312 daquele ano, este procedimento não encontra melhor sorte, sendo mantido praticamente o mesmo artigo constante na CLPS de 1976, vindo, o seu Regulamento, sequer tangenciar qualquer um dos pontos levantados na LOPS de 1960, como vimos.

A Lei n. 8213/91, por sua vez, não avançou muito se formos comparar com os dispositivos constantes na LOPS de 1960. Os pontos principais ressaltados como positivos, portanto, não foram recepcionados pela nova Lei de Benefícios da Previdência Social, nem pelo seu Decreto Regulamentador, de nº 3.48/99.

Não próximo e último tópico deste trabalho faremos um pequeno recorte do processo de reabilitação/habilitação profissional, analisando esse processo no ano de 2015, nas Agências de Previdência Social (APSs) que compõe a Gerência Exetutiva do INSS de Pelotas, no Rio Grande do Sul.

Interessa-nos, na análise dos dados quantitativos fornecidos pelo Setor de Reabilitação Profissional desta Instituição, fazer uma leitura qualitativa dos referidos dados, buscando responder as seguintes questões: a) será que os segurados estão tendo a oportunidade de participar deste programa, uma vez que é o INSS quem deve oferecer essa possibilidade?; b) existe uma equipe interdisciplinar para dar conta desse processo?; c) o programa de reabilitação/habilitação profissional possui convênios educativos e acordos de cooperação com empresas como parte do processo?; d) está fornecendo órteses e próteses para os segurados reabilitandos?; e) entre as patologias apontadas nos relatórios médicos constam as doenças relacionadas à saúde mental dos segurados?

Estas cinco questões, que esperamos responder a partir dos dados qualitativos fornecidos pelo setor respectivo da GEX-Pelotas, são fundamentais para que tenhamos uma pequena, mas significativa, amostra de como este processo reabilitatório e habilitatório está (ou) não ocorrendo no ínsito das políticas públicas previdenciárias. 


\section{UM RECORTE DO PROGRAMA DE} HABILITAÇÃO/REABILITAÇÃO NO ANO DE 2015 EM PELOTAS, RGS.

Antes de adentrarmos na análise dos dados colhidos, para os fins propostos nesta pesquisa, importante tecer algumas considerações, teóricas e práticas, sobre o procedimento da reabilitação e habilitação profissional.

Com efeito, uma primeira questão emerge no tocante à própria designação do nome do Programa, suscitando de plano uma análise conceitual sobre a significação deste processo.

É necessário que se diga que talvez esse ponto seja um dos menos desenvolvidos pela doutrina, cingindo-se, quando encontrado nos livros e manuais previdenciários, a poucas linhas ou parágrafos sobre esse importante procedimento, à cargo do INSS.

Parece, nesse sentido, importante primeiramente fazermos uma relação e, ao mesmo tempo, distinção entre o a Reabilitação e a Habilitação profissional propriamente dita. Nesse sentido, a lição de Wladimir Novaes Martinez parece pertinente e elucidadora:

Habilitação não se confunde com reabilitação. A primeira é a preparação do inapto para exercer atividades, em decorrência de incapacidade física adquirida ou deficiência hereditária. A segunda pressupõe a pessoa ter tido aptidão e tê-la perdido por motivo de enfermidade ou acidente. Tecnicamente o deficiente não é reabilitado e, sim, habilitado.(MARTINEZ, 1999).

Por certo que um trabalhador rural que perde parte dos movimentos de algum membro, indispensável à sua atividade habitual, até poderá aprender a exercer outro mister. Isso somente será possível dentro de um processo em reeducativo em que aprenderá novas habilidades. Por isso a reabilitação profissional é exigida. Como bem observou Wladimir Novaes Martinez, o deficiente se habilita para um mister, eis que não teve a oportunidade até então de aprender determinada atividade.

No mesmo sentido Marcelo Leonardo Tavares, para quem "a habilitação profissional difere conceitualmente da reabilitação por se referir a serviço que tem por fim inserir pessoa pela primeira vez no mercado laboral" (TAVARES, 2005, p. 231). A reabilitação, seguindo esta linha, busca a reinserção do trabalhador ao mercado de trabalho. 
Com efeito, embora seja um processo interdisciplinar desde a sua origem, nascera vinculado ao Serviço Social, não havendo dúvidas na importância dos Assistentes Sociais na condução dos processos reinserção dos segurados ao mercado de trabalho.

Conforme aponta Iraydes Moesia Ferreira, estes programas buscam promover a dignidade do ser humano, bem como a reintegração psicossocial dos deficientes, por meio do desenvolvimento de suas capacidades residuais. (FERREIRA, 1985, p. 23)

Como bem observa Silene Tonelli Regatieri, esse processo deverá levar em conta algumas variantes em prol dos trabalhadores: não pode o recolocar na mesma atividade sem que haja um estudo de impacto dos efeitos e consequências deste retorno; deve considerar seu grau de instrução, bem como atentar para as medidas de prevenção das causas que ocasionaram o adoecimento, de modo que não mais voltem a acontecer. (REGATIERI, 2014, p. 87).

No Manual Técnico de Procedimentos da Área de Reabilitação Profissional, organizado pela Diretoria de Saúde do Trabalhador (DIRSAT), ${ }^{5}$, esse processo é apresentado, no Capítulo II, como REABILITAÇAO PROFISSIONAL, cuja conceituação assim pode ser resumida: a Reabilitação Profissional é uma assistência educativa ou reeducativa, tanto de adaptação ou de readaptação profissional, cuja denominação genericamente é chamada de habilitação e reabilitação profissional. Busca, assim, proporcionar aos beneficiários incapacitados, parcial ou totalmente, em caráter obrigatório, independente de possuírem ou não qualquer carência, bem como aos portadores de deficiência, os meios de reingresso ao mercado de trabalho e no contexto em que vivem.

Adentrando no conceito de HABILIAÇÃO e REABILITAÇÃO, encontramos também uma certa distinção, a saber: A) Habilitação é a capacitação do segurado e seus dependentes para o exercício de uma atividade laborativa, devendo ser consideradas suas experiências, aptidões e interesses. B) Readaptação Profissional é o processo que busca tornar o segurado apto para retornar às suas atividades profissionais,

5 MANUAL TÉCNICO DE PROCEDIMENTOS DA ÁREA DE REABILITAÇÃo PROFISSIONAL. Diretoria de Saúde do Trabalhador (DIRSAT). Previdência Social. Nov. 2011. 
proporcionando-lhe os meios de adaptação às funções competíveis com suas limitações. (REGATIERI, 2014, p. 14).

No Capítulo IV é disposto o modo de formação das Equipes de Atendimento da Reabilitação Profissional, restando identificado o carácter inter e multidisciplinar de toda a equipe, prevendo a presença de sssistentes sociais, psicólogos, terapeutas ocupacionais, fisioterapeutas, sociológos e outros profissionais de áreas afins.

Este Manual revela a complexidade que deve permear esse processo reabilitatório/habilitatório: acordos de cooperação técnica, a formação de oficinas e cursos de educação pedagógica, a presente de equipes volantes para melhor atender aos segurados, avaliação constante, periódica, inclusive após o término do procedimento ${ }^{6}$, estágios curriculares e extracurriculares para os alunos graduados; o acompanhamento direto e periódico do habilitando/reabilitando, com a emissão de pareceres e relatórios; o fornecimento de suporte, desde a concessão das passagens utilizadas no trajeto ao fornecimento de próteses e órteses para que o segurado possa ser reabilitado/habilitado; entre outros tantos procedimentos constantes no procedimento.

Ao final do processo, é obrigado a emissão de um certificado em que conste quais são as eventuais ou prováveis atividades que o segurado poderá vir a exercer.

Diante disso, realizamos uma análise específica do processo de habilitação e de reabilitação profissional, tomando como base o ano calendário de 2015 (de 01/01/15 a 31/12/15), no sistema existente na Regional de Pelotas, no Rio Grande do Sul. ${ }^{7}$

A Gerência Executiva da Regional do INSS de Pelotas abrange, além desta cidade, mais dez cidades, quais sejam: Bagé, Camaquã, Jaguarão, Piratini, Rio Grande, São Lourenço do Sul, Canguçu, Santa Vitória do Palmar, Tapes e Capão do Leão.

\footnotetext{
${ }^{6}$ Existe a previsão de uma pesquisa bastante interessante denominada "Pesquisa de Fixação no Mercado de Trabalho", na qual os segurados que terminam o processo são entrevistados, respondendo a várias questões que serão posteriormente processadas e divulgadas em boletins institucionais, nos seis e nos doze meses subsequentes ao término do processo reabilitatório/habilitatório. Como veremos, no caso de Pelotas, RS, essa importante pesquisa não ocorre em virtude da falta de servidores ou pesquisadores que apliquem o instrumento.

${ }^{7}$ Estes dados, nos fornecido pelo Setor responsável pelo procedimento de Reabilitação Profissional em funcionamento na Agência de Previdência Social de Pelotas, RS, foram organizados a partir dos relatórios constantes no sistema MPAS/DATAPREV, no dia 19 de ago. 2016.
} 
Existem quatro equipes de Reabilitação/Habilitação Profissional organizadas nas seguintes cidades: Pelotas, Rio Grande, Bagé e Camaquã.

Buscando responder às questões levantadas no final do item 3.3, no que respeita ao caráter inter e multidisciplinar previsto na legislação e reiterado de forma esmiuçada no próprio Manual de procedimentos do INSS, constante na nota n. 197, resta prejudicado esse quesito em virtude de ter, na cidade de Pelotas que é a maior APS, somente um médico, uma psicóloga e cinco assistentes sociais. Nas demais cidades, existe somente um médico e um assistência social em cada equipe.

Quadro I - Total de Benefícios Requeridos e Benefícios Concedidos em 2015

\begin{tabular}{|l|c|c|}
\hline CIDADE SEDE DA APS & BENEFÍCIOS REQUERIDOS & $\begin{array}{l}\text { BENEFÍCIOS } \\
\text { CONCEDIDOS }\end{array}$ \\
\hline BAGÉ & 3.566 & 1.832 \\
\hline CAMAQUÃ & 2.785 & 1.258 \\
\hline JAGUARÃO & 835 & 386 \\
\hline PELOTAS & 9.061 & 4.851 \\
\hline PIRATINI & 37 & 28 \\
\hline RIO GRANDE & 5.333 & 3.477 \\
\hline SÃO L. DO SUL & 1.448 & 995 \\
\hline CANGUÇU & 1.964 & 1.196 \\
\hline $\begin{array}{l}\text { SANTA VITÓRIA } \\
\text { PALMAR }\end{array}$ & 628 & 467 \\
\hline TAPES & 842 & 460 \\
\hline CAPÃO DO LEÃO & 762 & 402 \\
\hline
\end{tabular}

Fonte: Organizado pelos autores.

Analisando e interpretando os dados referentes ao Quadro I, veremos que a Previdência Social concedeu em torno de $56 \%$ dos benefícios solicitados pelos segurados, frisando-se que estes dados resultam da soma de todos os auxílios-doenças comum (B-31) e dos auxilio-doenças acidentários (B-91), requeridos nestas APSs que formam a Regional de Pelotas, RS.

Quadro II - Perícias Realizadas e Processos de Habilitação/Reabilitação existentes em 2015 
José Ricardo Caetano Costa \& Ana Maria Correa Isquierdo

\begin{tabular}{|l|l|c|}
\hline CIDADE SEDE DA APS & TOTAL PERÍCIAS FEITAS & $\begin{array}{l}\text { TOTAL DE PROCESSOS DE } \\
\text { HAB./REAB. }\end{array}$ \\
\hline BAGÉ & 7.205 & 285 \\
\hline CAMAQUÃ & 4.262 & 65 \\
\hline JAGUARÃO & 2.735 & 7 \\
\hline PELOTAS & 16.551 & 355 \\
\hline PIRATINI & 260 & 2 \\
\hline RIO GRANDE & 11.542 & 231 \\
\hline SÃO L. DO SUL & 2.874 & 27 \\
\hline CANGUÇU & 3.624 & 43 \\
\hline SANTA V. PALMAR & 1.465 & 24 \\
\hline TAPES & 1.528 & 14 \\
\hline CAPÃO DO LEÃO & 1.269 & 4 \\
\hline
\end{tabular}

FONTE: Organizado pelos autores.

No Quadro II, temos a quantidade de perícias realizadas nestas APSs, bem como a quantidade de segurados que ingressaram em processo de reabilitação/habilitação profissional no ano de 2015.

Neste passo, vemos que foram realizadas 53.315 perícias médicas, somando-se igualmente os B-31 ao B-91, no ano de 2015. Por outro lado, estão em processo de habilitação/reabilitação profissional 1.057 segurados. Esses dados nos permitem afirmar que não chega à $2 \%$ o número de segurados que estão realizando esse procedimento reabilitatório/habilitatório.

Tal fato certamente tem como origem o dado já levantado neste item da pesquisa: o fato de ter um médico apenas em cada Equipe que compõe a Reabilitação Profissional, demonstrando a absoluta impossibilidade estrutural no atendimento de um número maior de segurados, muito embora os dados apontam pelo grande volume de empregados que estão em gozo de um dos benefícios por incapacidade temporária (comum e acidentário).

Em relação aos cursos de reeducação, bem como aos convênios e acordos de cooperação que a Previdência Social deve firmar para instrumentalizar esse processo, os dados colhidos junto à Equipe de Reabilitação Profissional de Pelotas, RS, não são nada 
animadores. Segundo o relato das Assistentes Sociais que trabalham neste Setor especializado na recuperação dos segurados, até o final do ano de 2014 a Previdência Social, pelo menos na Agência local analisada, eram comprados os cursos junto ao sistema conhecido como "5 S", especialmente no SESC, SESI, SENAI e SENAC. Estes convênios interinstitucionais foram suspensos ou rompidos a partir do começo de 2015 , de modo que, ao tempo em que foram colhidas estas informações (agosto de 2016), não existia absolutamente NENHUM CURSO em andamento no programa. O único encaminhamento, no sentido de aprimoramento pedagógico, foi no sentido de encaminhar aqueles segurados que não detinham ainda o Ensino Fundamental, com encaminhamento ao EJA (Educação de Jovens e Adultos).

Em relação aos cursos em que os segurados que participavam do Programa de RP eram inseridos, também a partir do começo de 2015 não vieram mais verbas para a participação junto ao PRONATEC $^{8}$, fazendo cessar os convênios, cursos técnicos e profissionalizantes.

Sem a existência de cursos reeducativos, bem como a impossibilidade de convênios institucionais e com empresas privadas, torna-se inviável sequer pensar em reinserção dos segurados no mercado de trabalho. Tais fatos certamente estão na base da pouquíssima utilização do sistema de habilitação e reabilitação profissional à cargo do INSS.

No que respeita ao fornecimento de próteses e órteses ${ }^{9}$, os dados relativos ao fornecimento de ambos demonstram o descaso com a saúde e recuperação dos trabalhadores. No ano de 2014 foram realizados somente 12 procedimentos, enquanto no ano de 2015 e até agosto de 2016 (data da investigação e coleta dos dados ora apresentados), NENHUMA prótese ou órtese foi disponibilizada aos 68 segurados em

\footnotetext{
${ }^{8}$ O Programa Nacional de Acesso ao Ensino Técnico e Emprego (Pronatec) foi criado pelo Governo Federal, em 2011, por meio da Lei 12.513/2011, com o objetivo de expandir, interiorizar e democratizar a oferta de cursos de educação profissional e tecnológica no país. O Pronatec busca ampliar as oportunidades educacionais e de formação profissional qualificada aos jovens, trabalhadores e beneficiários de programas de transferência de renda. Fonte: http://portal.mec.gov.br/pronatecl. Acesso em 19 agos. 2016.

9 A diferença entre elas é que na órtese é utilizado um aparelho ou equipamento que corrige alguma deformidade, auxiliando o organismo na função, enquanto a prótese é um aparelho ou equipamento que substitui o órgão ou sua função. Ambos são fundamentais, e a legislação previdenciária prevê que o INSS arque com estes aparelhos quando for necessário, para que o segurado possa recuperar pelo menos parte do movimento ou função prejudicada.
} 
processo de reabilitação/habilitação profissional que aguardam em uma longa e angustiante fila de espera.

Outro dado fornecido pela Gerência Executiva de Pelotas (GEX), retirado da mesma fonte dos demais dados apresentados, diz respeito ao número de segurados que começaram a participar do processo de habilitação e reabilitação profissional, no mesmo ano calendário de 2015, bem como os tipos de patologias que apresentaram.

Foram inscritos neste programa 343 segurados, podendo ser enquadrados nas seguintes patologias: ${ }^{10}$

\begin{tabular}{|l|l|}
\hline ESPÉCIES DE PATOLOGIAS & NÚMERO DE SEGURADOS \\
\hline TRAUMATOLOGIA E ORTOPEDIA & 230 \\
\hline PRESSÃO ARTERIAL ALTERADA & 21 \\
\hline DOENÇA MENTAL & 13 \\
\hline NEOPLASIA & 11 \\
\hline PROBLEMAS VISUAIS & 9 \\
\hline
\end{tabular}

Fonte: Organizado pelos autores.

Os dados ora entabulados nos permitem uma série de ilações. Para os fins propostos neste trabalho, porém, nos restringiremos a apresentar algumas leituras que podem auxiliar na reflexão que buscamos trazer.

Primeiro, é de se frisar que não é surpresa que $67 \%$ dos reabilitandos/habilitandos portem alguma patologia de origem traumatológica e ortopédica. Estes são realmente os casos mais indicados para esse processo. Caso típico que quem perde uma função ou movimento, decorrente de acidente do trabalho, mas pode vir, diante de um processo gradual, a retornar ao mercado de trabalho.

De qualquer modo cabe pelo menos duas observações quanto a esse elevado número, que beira aos 70\% das patologias registrada no sistema da GEX-Pelotas, RS. Vejamos: a) diante da escassez de perito médico com especialidade em psiquiatria, eis que existe um apenas em toda a Regional de Pelotas, conforme vimos, facilmente um

\footnotetext{
${ }^{10}$ Para fazer este quadro utilizamos o seguinte critério: agrupamos as patologias em cinco grandes grupos, a partir da CID 10: a) Traumatologia/Ortopedia/ b) Pressão Alterada; c) Doenças de origem mental; d) Neoplasias (malignas e benignas) e d) Relacionadas à Perda da Visão. Consideramos, para tanto, a quantidade de patologias superior a cinco casos, razão pela qual não elencamos as demais.
} 
segurado que se apresenta com um problema de LER/DORT também possui outras síndromes de origem psíquica e mental, o que é bem comum, mas que não aparecem no diagnóstico e nem durante o processo de recuperação laboral; b) o Setor de RP não possui sequer uma psicóloga e um terapeuta ocupacional, o que torna impossível qualquer possibilidade de recuperação de um segurado que precisa de tratamento nesta área. Isso porque não é possível pensar que uma qualificação acadêmica ou um curso técnico irá resolver no tratamento destas síndromes cada vez mais em crescente.

Por outro lado, diante da majoritária parcela de segurados que possuem problemas traumatológicos e ortopédicos, não é possível que grande parte deles, que estão em uma lista de espera aguardando pelas próteses e órteses, possam vir a ser reabilitados para algum mister caso não recebam estes equipamentos.

De qualquer modo, os 13 casos de doenças mentais apontados, que estão em processo de RP, já ocupando o terceiro lugar na lista das patologias que ensejam esse processo, não podem ser desprezados. Pelo contrário. Supõe-se que esse número seja muito maior. Seja pela dificuldade destas patologias serem detectadas quando das avaliações períciais, como vimos, seja pela falta de estrutura das Equipes de Reabilitação em decorrência da falta absoluta de profissionais para as compor.

\section{CONSIDERAÇÕES FINAIS}

Parece inconteste que o conceito de doença e de patologia passou por uma enorme evolução, especialmente depois da promulgação da Classificação Internacional de Deficiências, Incapacidades e Limitações (CIF), pela Organização Mundial de Saúde, de 2001, de modo que passou a ser considerado também o ambiente do trabalho e seu entorno. Isso porque, nessa nova concepção que passou a ser denominada de biopsicossocial, interessa predominantemente à falta de saúde do trabalhador, muito mais do que meramente qual é o Código Internacional da Doença (CID) que este possui. Importa, a partir desta concepção, conhecer o meio ambiente em que o trabalhador vive, sua participação na sociedade, o acesso às políticas públicas, suas atividades e participações, seu acesso à informação, entre outros fatores que passam a ser considerados. 
Além disso, a Convenção de Nova Iorque, recepcionada pelo Brasil com "status" de Emenda Constitucional, forneceu nova concepção de deficiência, ampliando-se, uma vez que, segundo esta Convenção, também é deficiente aqueles trabalhadores que passam a ter uma incapacidade laboral mais duradoura. No Brasil, a Lei n. 12.435/11 passou a entender como incapacidade duradoura aquela que perdura por dois anos ou mais. Com isso, o entendimento da própria concepção de deficiente para fins de recebimento do benefício assistencial da LOAS (Lei n. 8.742/93), foi ampliado de forma a contemplar um número maior de usuários.

Outra implicação desta nova concepção pode ser encontrada na nova Aposentadoria Especial dos Deficientes, prevista na Lei Complementar n. 142/13 e regulada pelo Dec. 145/13. Segundo a sistemática adotada na aferição das deficiências e incapacidades duradouras destes segurados, a avaliação deverá ser feita de forma mais complexa e globalizante, envolvendo a perícia médica e a perícia social de forma interdependente mas concomitante, garantindo que todas aqueles fatores elencados na CIF-2001 sejam considerados.

O Estatuto da Pessoa com Deficiência, por sua vez, introduzido pela Lei $\mathrm{n}^{\circ}$ 13.146/15, consolidou a concepção de deficiência em um sentido largo, complexo, pluridimensional, podendo ser compreendido, portanto, somente a partir de uma concepção igualmente pluridimensional, interdisciplinar. Frise-se que já no parágrafo único do seu primeiro artigo faz constar que a base desta lei de inclusão da pessoa com deficiência é a própria Convenção de Nova Iorque. E mais, aponta em seu parágrafo $2^{\circ}$, do art. $2^{\circ}$, que "a avaliação da deficiência, quando necessária, será biopsicossocial, realizada por equipe multiprofissional e interdisciplinar...", dando o prazo até o dia 05 de dezembro de 2017 para que as políticas públicas passem a operar nesta dinâmica.

Por outro lado, podemos observar que o tratamento atual dado aos benefícios por incapacidade está caminhando em sentido contrário do disposto no presente trabalho. A Medida Provisória $n^{\circ} 739$, de 07/07/16, bem como a sua sucessora, a MP $n^{\circ} 767 / 17$, alterou significativamente a dinâmica de concessão e manutenção dos benefícios por incapacidade. Como principal ponto podemos destacar o objetivo, nada velado, de revisar a qualquer tempo (quiçá, a qualquer custo), os benefícios por incapacidade (auxílios-doença e aposentadorias por invalidez). A começar pelos benefícios mais 
antigos, esta Medida Provisória prevê uma remuneração extraordinária para os peritos do INSS, como incentivo que cumpram esse mister o mais rápido possível. Afora isso, e talvez tão grave quanto, resta estabelecido uma certa "alta programada legal", préfixando um prazo de 120 dias, tão-somente, para o gozo dos benefícios do auxíliodoença, sempre que não for fixada pelo perito médico a suposta data de recuperação (milagrosa, certamente) da capacidade laboral. Ao que tudo indica, estas duas MPs trazem consigo um objetivo bem claro de redução de despesas do Ente Público para com os segurados da Previdência Social. Mais uma, entre tantas outras medidas para reformar o sistema mediante a retirada ou supressão de direitos sociais.

Todavia, pensamos ter demonstrado que as políticas públicas de seguridade social, envolvendo a Saúde, a Previdência e a própria Assistência Social, ainda não estão entrelaçadas no Brasil.

Com efeito, se a Constituição de 1988 trouxe um conceito de Seguridade Social nunca antes visto em nenhuma Constituição anterior, como vimos, também é verdade que as áreas que a compõe sempre foram vista de formas independentes e sem comunicação. A começar pela criação de Ministérios específicos (da Previdência, da Saúde e do Desenvolvimento Social), bem como pelos órgãos peculiares a cada uma destas áreas (INSS, SUS, SUAS), perdeu-se uma concepção integrativa e associativa que todas deveriam ter, confluindo em prol dos trabalhadores nos momentos de adoecimento e perda da capacidade laboral.

Ao que tudo indica é talvez essa "falha" representada pela desconexão entre as três espécies que compõe a Seguridade Social que permita-nos apontar como um dos motivos da precariedade com que o processo de habilitação/reabilitação se apresentada nos dias atuais.

Sendo o Processo de Reabilitação/Habilitação Profissional fundamental na reinserção dos trabalhadores que adoecem, no mercado de trabalho, ele faz uma ponte (ou deveria fazer) diretamente da Saúde com a Previdência, mas também com os benefícios assistenciais pois compete a ele o despertar de novas habilidades e aptidões dos deficientes. 
Muito embora saibamos que se trata de uma pequena amostragem, os dados disponibilizados pela Previdência Social, conforme vimos no último tópico do presente trabalho, traduzem em um primeiro olhar a deficiência do sistema previdenciário na própria caracterização e identificação das patologias de origem psíquicas e mentais. A começar pelo número exíguo de peritos médicos que possuem especialidade em psiquiatria, ou seja, apenas um em toda a Regional, bem como pela qualidade com que as perícias são feitas - que não é uma critica somente nas perícias administrativas, mas também nas judiciais, como demonstrado.

Vários profissionais, à exemplo dos trabalhadores bancários, com a nova reestruturação do capitalismo passaram a sofrer um processo de cobrança relacionada a metas abusivas e nunca satisfeitas por completo. Aliado a isso, os assaltos cada vez mais constantes causam estresse pré e pós-traumáticos que desencadeiam várias síndromes de origem psíquica. Estes trabalhadores, quando avaliados pelas rápidas e superficiais perícias médicas realizadas no âmbito do INSS, são considerados aptos para retornar aos seus labores devido a uma análise meramente aparente, baseada em impressões subjetivas dos peritos a partir da apresentação (vestuário, higiene etc.) destes trabalhadores.

Por conseguinte, se estas patologias não são sequer identificadas nas perícias médicas, pelas razões que vimos, por certo que grande parcela destes trabalhadores não torna-se elegível para os processos de readequação e reeducação profíssional.

Mesmo assim, e os dados levantados na amostra colhida comprovam isso, as patologias de origem mental já despontam em um significativo terceiro lugar no que refere ao CID - 10, suscitando questionamentos no que respeita ao encaminhamento destas demandas. Isso porque, como também vimos, não existe médico especialista em psiquiatria nas equipes de reabilitação, não psicólogos, nem terapeutas ocupacionais, retirando, com isso, o caráter inter e multidisciplinar que estas equipes devem ter.

Não é possível pensarmos em um processo sério de reinserção dos trabalhadores ao mercado de trabalho sem que seja possível o fornecimento de próteses e órteses as quais necessitam para tanto. Não é possível, também, acreditar que é viável esse procedimento sem que o trabalhador tenha condições de realizar cursos profissionalizantes e reeducativos, oficinas, estágios, entre outras tantas atividades, 
como se tivesse, por conta e risco, que procurar um emprego para poder "sair" da reabilitação proposta.

Podemos afirmar, sem engano, que se tudo está indicando que a perícia para detectar a incapacidade laboral é biopsicossocial, também deve ser o processo de reabilitação e reabilitação profissional. Somente em uma concepção mais global, envolvendo não somente uma equipe interdisciplinar mas também a comunidade, o poder público, os convênios etc., poderá contribuir para o retorno dos trabalhadores ao mercado de trabalho.

Acreditamos, portanto, ter demonstrado o quão importante é pensarmos a política pública da Seguridade Social de forma integrada, em conjunto. Para tanto acreditamos que algumas sugestões podem ser propostas, tal como um crédito no próprio sistema público de saúde (S.U.S), pois este poderá subsidiar a Previdência Social nos exames, atestados, tratamento etc., necessários à recuperação dos segurados. Não cremos ser utopia, em seu sentido pejorativo, acreditar que qualquer processo de reinserção do trabalhador ao seu trabalho e ao próprio meio em que vive passa por um tratamento condigno junto ao SUS, bem como também à Assistência Social, por meio dos Centros de Apoio Biopsicossociais (CAPs), especialmente nos casos de tratamento da saúde mental.

\section{REFERÊNCIAS BIBLIOGRÁFICAS}

BEVERIDGE, William. O Plano Beveridge: relatório sobre o seguro social e serviços afins. Tradução de Almir de Andrade. Rio de Janeiro : José Olympio Editora, 1943.

BRAGA, Juliana; BOLSON, Pâmela; COSTA, José Ricardo Caetano. A Perícia Médica Judicial nos Juizados Especiais Federais sob Julgamento: um recorte pequeno de um grande problema. In: $35^{\circ}$ Congresso Brasileiro de Previdência Social - Básica e Complementar. Jornal do Congressso. São Paulo : LTr., 20 jun. 2016.

COSTA, Jose Ricardo Caetano. PERÍCIA BIOPSICOSSOCIAL- PERSPECTIVA DE UM NOVO MODELO PERÍCIAL, Caxias do Sul : Editora Plenum, 2014.

FERREIRA, Iraydes Moesia. Reabilitação Profissional \& Serviço Social. São Paulo : Editora Cortez, 1985.

MANUAL TÉCNICO DE PROCEDIMENTOS DA ÁREA DE REABILITAÇÃo PROFISSIONAL. Diretoria de Saúde do Trabalhador (DIRSAT). Previdência Social. Novembro 2011. 
MAUSS, Adriano; COSTA, José Ricardo Caetano. Aposentadoria Especial dos Deficientes: aspectos legais, processuais e administrativos. São Paulo : LTr., 2015.

MARTINEZ, Wladimir Novaes. CD - Comentários à Lei Básica da Previdência Social. Brasilia, Rede Brasil/LTr., fev./1999.

REGATIERI, Silene Tonelli. A Efetividade da Reabilitação Profissional Previdenciária em Face da Realidade do Trabalhador com Baixa Instrução. In: Revista de Direito Social. Ano 1, n. 62, p. 80-92, set.-out. 2014.

ROSA, Albino Pereira da. A Lei Orgânica da Previdência Social. Rio de Janeiro Editora Melso Soc. Anonima, s/d.

SAVARIS, José Antonio. Introdução ao Curso de Perícia Judicial Previdenciária: noções elementares para a comunidade médico-jurídica. In: SAVARIS, José Antonio. Curso de Perícia Judicial Previdenciária: noções elementares para a comunidade médico-jurídica. São Paulo : Editora Conceito, 2011.

SERAU Jr., Marco Aurélio; COSTA, José Ricardo Caetano (Orgs.). Benefício Assistencial: temas polêmicos. São Paulo : LTr., 2015.

(Orgs.). Assistance Benefits in Brazil: chances and challenges to the exercise of a constitucional right. Switzerland : Springer International Publisching Ag, 2016, v. 1, 197 p.

SOTTILI, Luciana Adélia; COSTA, José Ricardo Caetano. A Formação Humanística dos Médicos: uma análise comparativa dos currículos das principais faculdades de medicina de São Paulo e Rio Grande do Sul. In: 35 Congresso Brasileiro de Previdência Social - "Básica e Complementar". Jornal do Congresso. São Paulo : Editora LTr., 20 jun. 2016.

TAVARES, Marcelo Leonardo. Direito Previdenciário. Rio de Janeiro : Editora Lumen Juris, 2005, p. 231. 